\title{
Predicting the limits of the endoscopic endonasal approach in children: a radiological anatomical study
}

\author{
Carl A. Youssef, BS, ${ }^{1}$ Carmen R. Smotherman, MS, ${ }^{2}$ Dale F. Kraemer, $\mathrm{PhD},{ }^{2,3}$ and \\ Philipp R. Aldana, MD ${ }^{4}$ \\ 1 University of Florida College of Medicine, Office of Medical Education, Gainesville; ${ }^{2}$ Center for Health Equity and Quality \\ Research (CHEQR), and ${ }^{3}$ Department of Neurology, University of Florida College of Medicine Jacksonville; and ${ }^{4}$ University of \\ Florida College of Medicine Jacksonville and Wolfson Children's Hospital, Jacksonville, Florida
}

\begin{abstract}
OBJECTIVE The endoscopic endonasal approach (EEA) has been established as an alternative approach to craniovertebral junction (CVJ) pathology in adults. The authors have previously described the nasoaxial line (NAxL) as an accurate predictor of the lower limit of the EEA to the CVJ in adults. The surgical anatomy limiting the EEA to the pediatric CVJ has not been well studied. Furthermore, predicting the lower limit of the EEA in various pediatric age groups is important in surgical planning. To better understand the anatomy affecting the EEA to the CVJ, the authors examined the skull base anatomy relevant to the EEA in children of different age groups and used the NAxL to predict the EEA lower limit in children.
\end{abstract}
METHODS Axial brain CT scans of 39 children with normal skull base anatomy were reconstructed sagittally. Children were divided into 4 groups according to age: 3-6, 7-10, 11-14, and 15-18 years old. The intersection of the NAxL with the odontoid process of $\mathrm{C}-2$ was described for each group. Analyses of variance were used to estimate the effect of age, sex, interaction between age and sex on different anatomical parameters relevant to the endonasal corridor (including the length of the hard palate [HPLe]), dimensions of choana and piriform aperture, and the length of the NAxL to C-2. The effect of the HPLe on the working distance of NAxL to the odontoid was also estimated using analysis of covariance, controlling for age, sex, and their interaction.

RESULTS The NAxL extended to the odontoid process in 38 of the 39 children. Among the 39 children, the NAxL intersected the upper third of the odontoid process in 25 while intersecting the middle third in the remaining 13 children. The measurements of the inferior limits did not differ with age, varying between 9 and $11 \mathrm{~mm}$ below the hard palate line at the ventral surface of $\mathrm{C}-2$. Significant increases in the size of the piriform aperture and choana and the HPLe were observed after age 10. The HPLe predicted the length of the NAxL $(p<0.0001)$.

CONCLUSIONS The caudal limit of the EEA extends as far as the middle third of the odontoid process in children, as predicted by the NAxL. The most prominent increase in the size of the choana and piriform aperture occurs after age 10 . The HPLe is a significant predictor of the working distance to C-2. Utilizing the NAxL preoperatively may help in planning the EEA to the CVJ in children.

http://thejns.org/doi/abs/10.3171/2015.6.PEDS14695

KEY WORDS endonasal approach; craniovertebral junction; endoscopy; minimally invasive spine surgery; odontoidectomy; skull base surgery; pituitary surgery

$\mathrm{T}$ HE craniovertebral junction (CVJ) is an elaborate anatomical region that comprises the clivus, foramen magnum, and the atlantoaxial complex. CVJ abnormalities are especially relevant in the pediatric population. Many studies have documented the association between these lesions and disorders such as Down syndrome, osteogenesis imperfecta, juvenile rheumatoid ar- thritis, Klippel-Feil triad, and Morquio syndrome, among many others ${ }^{16,19,24}$ Additionally, neoplastic lesions constitute an important category of CVJ pathology in children. Although usually benign, these tumors are often resistant to chemotherapy and radiation, thus requiring surgical excision. ${ }^{17}$

Given the complex and deeply situated osteoligamen-

ABBREVIATION ANS = anterior nasal spine; $A O A=$ angle of attack; CVJ = craniovertebral junction; EEA = endoscopic endonasal approach; HPL = hard palate line; HPLe $=$ length of the hard palate; $\mathrm{NAxL}=$ nasoaxial line; $\mathrm{NC2}=$ working distance of NAxL to the odontoid process of C-2; PNS = posterior nasal spine; Rh = rhinion.

SUBMITTED December 26, 2014. ACCEPTED June 2, 2015.

INCLUDE WHEN CITING Published online November 27, 2015; DOI: 10.3171/2015.6.PEDS14695. 
tous and neurovascular anatomy, surgical management of CVJ disorders has been uniquely challenging. ${ }^{10,22}$ Traditionally, the transoral route has been the "gold standard" to ventral CVJ lesions. This approach, however, often necessitates invasive procedures, such as glossotomy and splitting of the soft palate to decompress lesions located high above the level of the palate. Significant oropharyngeal morbidity has led to prolonged hospitalization and slowed recovery. ${ }^{8,9,18}$

Advances in surgical techniques and neuroimaging modalities have allowed the development of several imageguided, minimally invasive approaches to the CVJ, including the endoscopic endonasal approach (EEA). ${ }^{6,711,12,14,15,20,21}$ This approach avoids the oropharyngeal complications of the traditional, open transoral approach, while providing a direct, less traumatic, and shorter route to the rostral CVJ. ${ }^{3}$ Several studies have demonstrated the feasibility of this approach to the entire ventral midline skull base in pediatric patients. ${ }^{12,15,23}$

One of the restrictions of the EEA to the CVJ, nonetheless, is its limited caudal exposure. Our group has previously described a novel method, the nasoaxial line (NAxL), to accurately predict the caudal limit of the EEA in adults. ${ }^{2}$ In this radiological anatomical study, we use the NAxL to predict the caudal limitation of the EEA in children. We also quantitatively measured several anatomical parameters that are relevant to the endonasal corridor in different pediatric age groups. Understanding the anatomical limitations of the EEA to the CVJ in children is a vital part of optimal preoperative planning for surgical management of various pathologies relevant to this complex area.

\section{Methods \\ Patient Selection}

The research protocol was approved by the Institutional Review Board at University of Florida College of Medicine Jacksonville to review CT scans of patients 18 years of age or younger. Scans were performed for evaluation of sinusitis between March and June 2013. Patients with skull base abnormalities as detected by the CT scan were excluded from the study. Patients with misaligned scans, defined as greater than $5^{\circ}$ of deviation from the midsagittal plane, were also excluded. A total of 39 patients with normal skull base anatomy and evenly aligned scans were identified, and stratified to 4 groups according to age at the time of the scan.

\section{Measurements}

Axial scans with slice thicknesses varying between 0.625 and $1.25 \mathrm{~mm}$ were loaded into OsiriX medical imaging software (version 4.1.2; Pixmeo). Images were then reconstructed in the sagittal plane. Distances were measured in millimeters and angles were measured in degrees.

Measurement techniques were similar to those previously described by our group. ${ }^{2}$ Most importantly, the NAxL is constructed in the midsagittal plane, starting from the midpoint of the distance between the rhinion $(\mathrm{Rh})$ to the anterior nasal spine (ANS) of the maxillary bone and passing through the posterior nasal spine (PNS) of palatine bone. The hard palate line (HPL) passes from the ANS to the PNS. The 2 lines intersect at the PNS, forming the vertex of the angle of attack (AOA). Both lines are then projected posteriorly to the CVJ. All other measurements are summarized in Table 1 and illustrated in Fig. 1.

\section{Statistical Analysis}

The intersection of the NAxL with the odontoid process of C-2 was described for each age group using simple descriptive counts. The Fisher's exact test was used to compare the positions of the intersection across the 4 age groups. Multivariable analyses were used to investigate the effect of age, sex, and interaction between age and sex on the different anatomical parameters relevant to the endonasal corridor. Because sex and the interaction of age and sex were not significant in any of these parameters and the addition of these terms did not improve the fit (using the corrected Akaike information criterion ${ }^{1,13}$ ), the models were refit with only age as a predictor (i.e., as univariable models). Least-square adjusted means were estimated and,

TABLE 1. Abbreviation definitions and measurements

\begin{tabular}{|c|c|c|c|c|}
\hline Abbreviation & Measurement & Method of Measurement & Plane & Figure \\
\hline $\mathrm{AOA}$ & Angle of attack & Angle between NAxL and HPL & Sagittal & $1 \mathrm{C}$ \\
\hline $\mathrm{CA}$ & Clival angle & Angle between ethmoidal plate and clival plane & Sagittal & $1 \mathrm{C}$ \\
\hline $\mathrm{CH}$ & Height of choanal aperture & Distance between floor of sphenoid sinus and PNS & Sagittal & $1 \mathrm{~A}$ \\
\hline CW & Width of choanal aperture & Distance between medial pterygoid plates & Axial & 1B \\
\hline $\mathrm{HC} 2$ & Distance between tip of dens of C-2 to HPL & $\begin{array}{l}\text { Vertical distance between tip of dens of C-2 inferiorly and } \\
\text { HPL superiorly }\end{array}$ & Sagittal & $1 \mathrm{C}$ \\
\hline $\mathrm{HC} 2 \mathrm{D}$ & Distance between NAxL and HPL at C-2 dorsally & Vertical distance between NC2 inferiorly and HPL superiorly & Sagittal & $1 \mathrm{C}$ \\
\hline $\mathrm{HC} 2 \mathrm{~V}$ & Distance between NAxL and HPL at C-2 ventrally & Vertical distance between NC2 inferiorly and HPL superiorly & Sagittal & $1 \mathrm{C}$ \\
\hline HPLe & Length of hard palate & Distance between ANS and PNS & Sagittal & $1 \mathrm{~A}$ \\
\hline NC2 & $\begin{array}{l}\text { Length of NAxL terminating in the cortex of the } \\
\text { dens }\end{array}$ & $\begin{array}{l}\text { Distance between starting point of NAxL and its intersection } \\
\text { with the ventral surface of the dens }\end{array}$ & Sagittal & $1 \mathrm{C}$ \\
\hline $\mathrm{PH}$ & Height of piriform aperture & Distance between Rh and ANS & Sagittal & $1 \mathrm{~A}$ \\
\hline PW & Width of piriform aperture & Distance between frontal processes of maxilla & Axial & $1 \mathrm{~B}$ \\
\hline
\end{tabular}




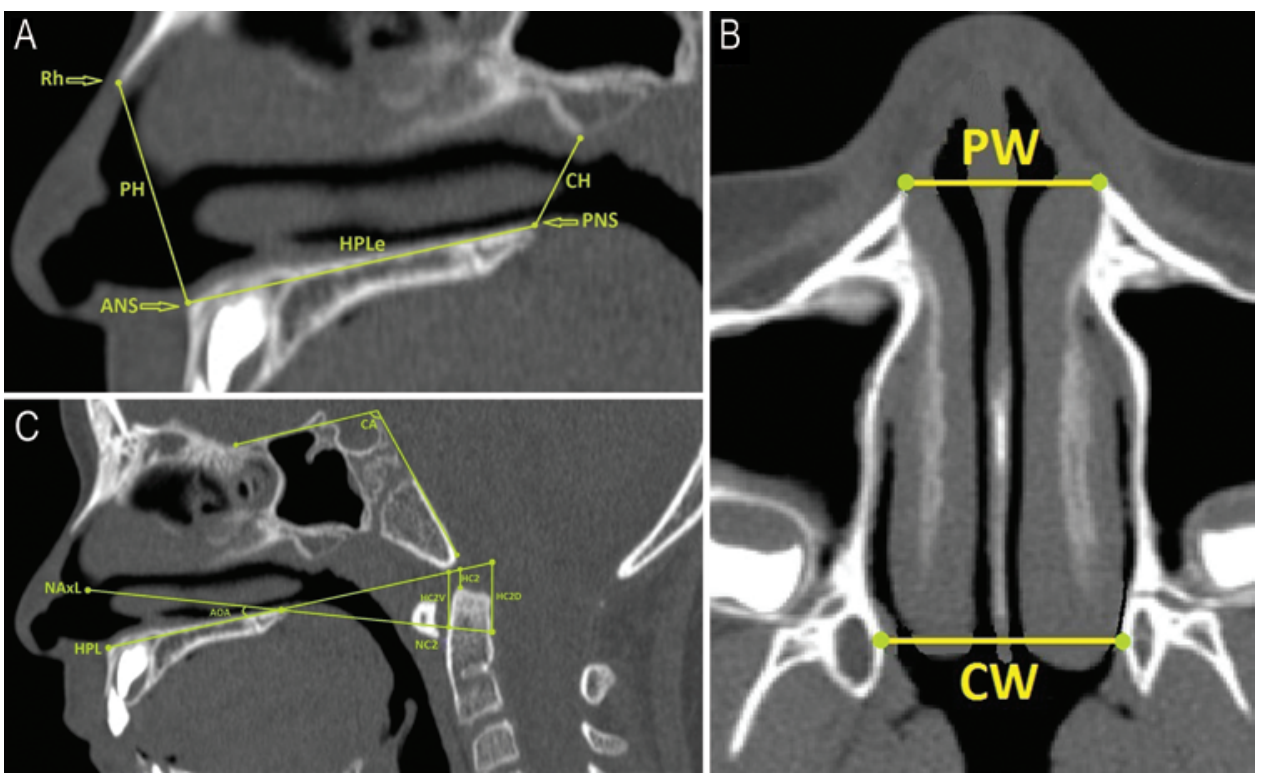

FIG. 1. Representative CT scans illustrating radiological landmarks and methods described in Table 1, in which some abbreviations are defined. A: Sagittal image of the nasopharynx illustrating the Rh, ANS, and PNS, along with HPLe and piriform and choanal aperture heights ( $\mathrm{PH}$ and $\mathrm{CH}$, respectively). B: Axial image of the nasopharynx illustrating piriform and choanal aperture widths (PW and CW, respectively). C: Sagittal image illustrating the NAxL, HPL, AOA, distance from the HPL to the intersection of the NAxL on C-2 ventrally (HC2V), dorsally (HC2D), and to the tip of the dens (HC2), and finally, clival angle (CA). Figure is available in color online only.

if there was a significant difference among the 4 groups $(\mathrm{p}<0.05)$, the age groups were compared pairwise with a Tukey-Kramer adjustment for multiple comparisons. Lastly, analysis of covariance was used to investigate the effect of the length of the hard palate (HPLe) on the working distance of NAxL to the odontoid process of C-2 (NC2), controlling for age, sex, and the interaction between age and sex. This model estimated a slope coefficient for relating HPLe to NC2, yielding an expected unit change in NC2 per unit change in HPLe.

\section{Results}

The CT scans of 39 children were analyzed, with a mean age of 10.8 years and standard deviation of 4.41. Median ages for each age group were as follows: 5.2 years ( $3-6$ years old; $n=10)$, 9.1 years $(7-10$ years old; $n=10)$, 13.3 years $(11-14$ years old, $n=10)$, and 16.2 years $(15-18$ years old; $n=9)$. No CVJ pathology was noted. The scans were analyzed for the anatomical parameters discussed above.

Table 2 demonstrates the intersection of the NAxL with the odontoid process of $\mathrm{C}-2$. Among the 39 children, the NAxL intersected the upper third of the odontoid process in 25 while intersecting the middle third in the remaining 13 children. The location of the intersection of the NAxL with $\mathrm{C}-2$ was similar across the 4 age groups $(p=0.23)$. The NAxL did not reach the odontoid process in only 1 child (13.7-year-old male).

A summary of the anatomical measurements relevant to the endonasal corridor is shown in Table 3, and agerelated changes in nasopharyngeal anatomy are illustrated in Figs. 2 and 3.
For the anatomical structures that affect the EEA to the CVJ, the piriform and choanal apertures, and the hard palate, patient age was the only variable that predicted the dimensions of these structures. There were significant differences among the age groups for piriform aperture height and width $(\mathrm{p}=0.0005$ and $\mathrm{p}=0.037)$, choanal height and width ( $\mathrm{p}<0.0001$ for both), and HPLe ( $\mathrm{p}=$ 0.0028). There were no significant differences among the age groups for the remaining anatomical parameters.

For piriform aperture height, there was a significant difference between age group $1($ mean $=20.8 \mathrm{~mm})$ and age group 3 (mean $=27.1 \mathrm{~mm}$; adjusted $\mathrm{p}=0.0004)$, and between age group $1($ mean $=20.8 \mathrm{~mm})$ and age group 4 (mean $=25.9 \mathrm{~mm}$; adjusted $\mathrm{p}=0.005)$; other pairs of means were not different from one another (Fig. 2A). While there was a significant difference among the age groups for piriform aperture width, no pair of means differed with the Tukey adjustment (Fig. 2B).

The mean choanal height and width were significantly different when comparing either age group 1 or group 2 with either age group 3 or group 4 (all $\mathrm{p} \leq 0.01$ ), after

TABLE 2. Portion of the dens of C-2 intersected by the NAxL

\begin{tabular}{ccc}
\hline $\begin{array}{c}\text { Intersection of NAxL } \\
\text { on C-2 (age in yrs) }\end{array}$ & $\begin{array}{c}\text { Upper Third } \\
\text { of Dens }\end{array}$ & $\begin{array}{c}\text { Middle Third } \\
\text { of Dens }\end{array}$ \\
\hline $3-6$ & 5 & 5 \\
\hline $7-10$ & 9 & 1 \\
\hline $11-14^{*}$ & 6 & 3 \\
\hline $15-18$ & 5 & 4 \\
\hline
\end{tabular}

* One patient in this age group had an NAxL passing above the tip of C-2. 
TABLE 3. Measurements of several skull base and endonasal anatomical parameters across different age groups

\begin{tabular}{ccccc}
\hline Measurement $^{*}$ & Ages 3-6 & Ages 7-10 & Ages 11-14 & Ages 15-18 \\
\hline $\mathrm{AOA}\left({ }^{\circ}\right)$ & 13.3 & 14.2 & 15 & 14.2 \\
\hline $\mathrm{CA}\left({ }^{\circ}\right)$ & 110.3 & 109.6 & 109.9 & 109.3 \\
\hline $\mathrm{CH}(\mathrm{mm})$ & 11.87 & 12.41 & 16.27 & 16.57 \\
\hline $\mathrm{CW}(\mathrm{mm})$ & 19.73 & 21.33 & 24.81 & 24.89 \\
\hline $\mathrm{HC} 2(\mathrm{~mm})$ & 2.77 & 3.82 & 1.88 & 0.02 \\
\hline $\mathrm{HC} 2 \mathrm{~mm})$ & 11.43 & 11.66 & 14.17 & 12.64 \\
\hline $\mathrm{HC} 2 \mathrm{(mm})$ & 9.57 & 9.46 & 11.36 & 40.15 \\
\hline $\mathrm{HPLe}(\mathrm{mm})$ & 40.24 & 43.31 & 46.03 & 96.37 \\
\hline $\mathrm{NC2}(\mathrm{mm})$ & 85.89 & 87.06 & 95.54 & 93.08 \\
\hline $\mathrm{PH}(\mathrm{mm})$ & 20.84 & 24.01 & 27.13 & 25.91 \\
\hline $\mathrm{PW}(\mathrm{mm})$ & 18.15 & 17.81 & 20.03 & 20.23 \\
\hline
\end{tabular}

* For definitions of abbreviations see Table 1.

Tukey adjustment for multiple comparisons; other pairs of means did not differ from one another (Fig. 2C and D).

The mean HPLe for age group 1 (mean $=40.2 \mathrm{~mm}$ ) was significantly different from age group 3 (mean $=46.0$ $\mathrm{mm} ; \mathrm{p}=0.008)$ and age group $4($ mean $=46.4 \mathrm{~mm} ; \mathrm{p}=$ 0.005 ), after Tukey adjustment for multiple comparisons; other pairs of means did not differ from one another (Fig. 3). The HPLe was a significant predictor of NC2 (p < 0.0001 ) when controlling for sex, age group, and interaction between sex and age group. For each 1-mm increase in HPLe, NC2 increased by $1.22 \mathrm{~mm}(95 \%$ CI $0.89-1.58$

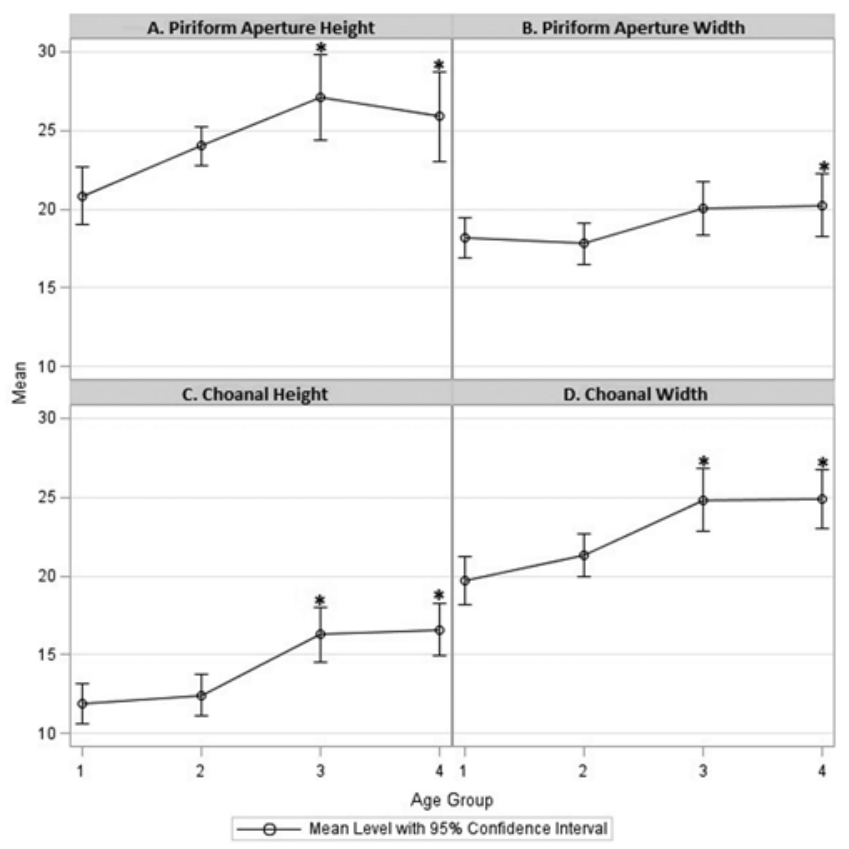

FIG. 2. Endonasal anatomical parameters and how they change with age in Group 1 (3-6 years old), Group 2 (7-10 years old), Group 3 (11-14 years old), and Group 4 (15-18 years old). A: Piriform aperture height. B: Piriform aperture width. C: Choanal height. D: Choanal width. ${ }^{*} p<0.05$. $\mathrm{mm}$ ), while all other variables in the model were held constant.

\section{Discussion}

The EEA has been established as an alternative surgical approach to the entire ventral midline skull base, from the cribriform plate to the foramen magnum. In our previous adult cadaveric-anatomical study, we determined that the inferior limit of the EEA can be accurately predicted by the NAxL. ${ }^{2}$ In this radiological anatomical study, we explored the anatomical limitations of the EEA in 39 children between 3 and 18 years of age with normal skull base anatomy. Using the NAxL to predict the lower limit of the EEA, we found that the predicted inferior limit of the EEA reaches as far as the middle third of the odontoid process of C-2. In about two-thirds of the children, the predicted inferior limit of the EEA was the upper third of the odontoid process, while in the remaining one-third, the predicted inferior limit was the middle third. These findings are comparable to the results from our adult study, in which we demonstrated the caudal extent of the EEA to

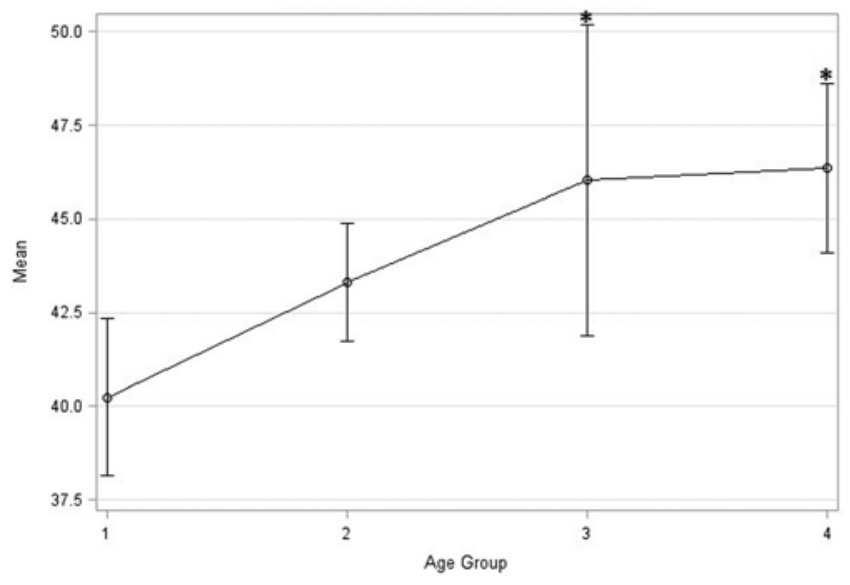

FIG. 3. Age-related change in HPLe. ${ }^{*} p<0.05$. 
be the upper half of C-2. ${ }^{2}$ The termination of the NAxL on the odontoid process (NC2) can be used to approximate the working distance of the EEA to the CVJ.

We found that the dimensions of the piriform aperture and choana and the length of the hard palate progressively increase with age. The most rapid increase in size was observed in age group 3 (11-14-year-olds), which likely corresponds to the rapid growth changes during puberty, explaining the larger difference in these parameters when comparing age groups 1 and 2 (children younger than 10) with age groups 3 and 4 (those older than 10). These agerelated changes provide evidence that the skull base also undergoes a "growth spurt" during puberty.

Few studies have attempted to characterize the anatomical changes and growth patterns that take place during the skull base developmental process, with the majority of these studies focusing on sphenoid bone development, pneumatization, and intercarotid distance at different intracranial levels. Tatreau et al. ${ }^{25}$ assessed the piriform aperture as a potential restriction site to the endonasal approach in children. It was shown that the width of the piriform aperture, measured as the maximal transverse distance on the coronal plane, increases steadily across the different age groups, with a significant difference only between infants younger than 2 years and adults. In our study, we found a similar progressive increase in the width of the piriform aperture, measured on the axial plane, but statistically significant increases were detected earlier, starting in children older than 10 years.

Endonasal anatomical restriction sites were further studied by Banu et al., ${ }^{5}$ measuring the maximum distances between the middle and inferior turbinates. However, no clear growth patterns were observed using this method. In our study, these measurements correspond most closely with the axially restricting choanal width, which we have shown to increase significantly in children older than 10 years. In fact, the mean choanal width in children between 3 and 10 years old was $20.5 \mathrm{~mm}$, divided by the vomer into approximately two $10.25-\mathrm{mm}$ apertures. This presents an important anatomical limitation of the endonasal corridor in children; thus, the uninostril approach possible in older children and adults may not be feasible in younger children. Considering the need to advance surgical instruments through the choanal aperture, even with resection of the posterior nasal septum, the small working space imposed by the choana may necessitate a binostril approach in young children.

Banu et al. ${ }^{4}$ also evaluated working distances from the nares to various intracranial targets, such as the odontoid process. The nare-dens distance, measured as the horizontal distance between the anterior nasal spine and the odontoid process of C-2, was found to increase steadily across age groups. However, based on our previous study, ${ }^{2}$ the distances reported using this method likely result in an overestimation of the working distance to the CVJ using the EEA.

There are some limitations to our study. Due to the lack of availability of pediatric cadaveric specimens, this study is purely radiological, given that anatomical dissections are not feasible. Thus, the inferior limits of the EEA in children, as predicted by the NAxL, need further clinical or cadaveric validation. Also, only children with normal skull base anatomy were included in this study, making the results not generalizable to children with anatomical skull base abnormalities, such as basilar invagination. The size of the nares was not included in our analysis due to the considerable variability in the anatomical orientation of the nares and the consequent absence of a reliable and accurate radiological method to measure its dimensions. The small sample size of the study may also limit our findings. Lastly, our study did not include children younger than 3 years old, and the applicability of the EEA and its caudal limitation in this age group remain uncertain and necessitates further assessment.

\section{Conclusions}

The EEA is an established alternative approach in the surgical management of ventral CVJ lesions in adults but has not been as well studied in children. In this study, we used the NAxL method to predict the caudal limit of this approach in different age groups of children with normal skull base anatomy. We predict that the EEA can expose as far inferiorly as the middle third of the odontoid process of C-2. We also demonstrated the changes in the size of the piriform and choanal apertures and the HPLe with age, with the most significant changes occurring during puberty. The findings in this study shed more light on the development of the pediatric skull base and can assist in the presurgical planning of pediatric patients with CVJ pathology. This study provides the surgeon with knowledge regarding the endoscopic skull base anatomy in children as well as a tool, the NAxL, to assess the inferior limit of the EEA to the various pathologies encountered in this complex region.

\section{Acknowledgments}

We wish to thank Jennifer Santarone for manuscript editing and preparation.

\section{References}

1. Akaike H: Factor Analysis and AIC. Psychometrika 52:317-332, 1987

2. Aldana PR, Naseri I, La Corte E: The naso-axial line: a new method of accurately predicting the inferior limit of the endoscopic endonasal approach to the craniovertebral junction. Neurosurgery 71 (2 Suppl Operative):ons308-314, 2012

3. Baird CJ, Conway JE, Sciubba DM, Prevedello DM, Quiñones-Hinojosa A, Kassam AB: Radiographic and anatomic basis of endoscopic anterior craniocervical decompression: a comparison of endonasal, transoral, and transcervical approaches. Neurosurgery $65(6$ Suppl):158-163, 63-64, 2009

4. Banu MA, Guerrero-Maldonado A, McCrea HJ, GarciaNavarro V, Souweidane MM, Anand VK, et al: Impact of skull base development on endonasal endoscopic surgical corridors. J Neurosurg Pediatr 13:155-169, 2014

5. Banu MA, Rathman A, Patel KS, Souweidane MM, Anand VK, Greenfield JP, et al: Corridor-based endonasal endoscopic surgery for pediatric skull base pathology with detailed radioanatomic measurements. Neurosurgery 10 (Suppl 2):273-293, 2014

6. Cavallo LM, Cappabianca P, Messina A, Esposito F, Stella L, de Divitiis E, et al: The extended endoscopic endonasal ap- 
proach to the clivus and cranio-vertebral junction: anatomical study. Childs Nerv Syst 23:665-671, 2007

7. Cavallo LM, Messina A, Cappabianca P, Esposito F, de Divitiis E, Gardner P, et al: Endoscopic endonasal surgery of the midline skull base: anatomical study and clinical considerations. Neurosurg Focus 19(1):E2, 2005

8. Crockard HA: Transoral surgery: some lessons learned. Br J Neurosurg 9:283-293, 1995

9. Di Lorenzo N: Craniocervical junction malformation treated by transoral approach. A survey of 25 cases with emphasis on postoperative instability and outcome. Acta Neurochir (Wien) 118:112-116, 1992

10. Doglietto F, Prevedello DM, Jane JA Jr, Han J, Laws ER Jr: Brief history of endoscopic transsphenoidal surgery-from Philipp Bozzini to the First World Congress of Endoscopic Skull Base Surgery. Neurosurg Focus 19(6):E3, 2005

11. Kassam AB, Snyderman C, Gardner P, Carrau R, Spiro $\mathrm{R}$ : The expanded endonasal approach: a fully endoscopic transnasal approach and resection of the odontoid process: technical case report. Neurosurgery 57 (1 Suppl):E213, 2005

12. Kassam A, Thomas AJ, Snyderman C, Carrau R, Gardner P, Mintz A, et al: Fully endoscopic expanded endonasal approach treating skull base lesions in pediatric patients. J Neurosurg 106 (2 Suppl):75-86, 2007

13. Kramer CY: Extension of multiple range tests to group means with unequal numbers of replications. Biometrics 12:307310,1956

14. Leng LZ, Anand VK, Hartl R, Schwartz TH: Endonasal endoscopic resection of an os odontoideum to decompress the cervicomedullary junction: a minimal access surgical technique. Spine 34:E139-E143, 2009

15. Locatelli D, Rampa F, Acchiardi I, Bignami M, Pistochini A, Castelnuovo P: Endoscopic endonasal approaches to anterior skull base defects in pediatric patients. Childs Nerv Syst 22:1411-1418, 2006

16. Menezes AH: Craniovertebral junction database analysis: incidence, classification, presentation, and treatment algorithms. Childs Nerv Syst 24:1101-1108, 2008

17. Menezes AH: Craniovertebral junction neoplasms in the pediatric population. Childs Nerv Syst 24:1173-1186, 2008

18. Menezes AH: Surgical approaches: postoperative care and complications "transoral-transpalatopharyngeal approach to the craniocervical junction." Childs Nerv Syst 24:11871193,2008

19. Menezes AH: Craniocervical fusions in children. J Neurosurg Pediatr 9:573-585, 2012
20. Messina A, Bruno MC, Decq P, Coste A, Cavallo LM, de Divitiis E, et al: Pure endoscopic endonasal odontoidectomy: anatomical study. Neurosurg Rev 30:189-194, 2007

21. Nayak JV, Gardner PA, Vescan AD, Carrau RL, Kassam AB, Snyderman CH: Experience with the expanded endonasal approach for resection of the odontoid process in rheumatoid disease. Am J Rhinol 21:601-606, 2007

22. Prevedello DM, Doglietto F, Jane JA Jr, Jagannathan J, Han J, Laws ER Jr: History of endoscopic skull base surgery: its evolution and current reality. J Neurosurg 107:206-213, 2007

23. Shah RN, Surowitz JB, Patel MR, Huang BY, Snyderman $\mathrm{CH}$, Carrau RL, et al: Endoscopic pedicled nasoseptal flap reconstruction for pediatric skull base defects. Laryngoscope 119:1067-1075, 2009

24. Taggard DA, Menezes AH, Ryken TC: Treatment of Down syndrome-associated craniovertebral junction abnormalities. J Neurosurg 93 (2 Suppl):205-213, 2000

25. Tatreau JR, Patel MR, Shah RN, McKinney KA, Wheless SA, Senior BA, et al: Anatomical considerations for endoscopic endonasal skull base surgery in pediatric patients. Laryngoscope 120:1730-1737, 2010

\section{Disclosures}

The authors report no conflict of interest concerning the materials or methods used in this study or the findings specified in this paper.

\section{Author Contributions}

Conception and design: Aldana. Acquisition of data: Aldana, Youssef. Analysis and interpretation of data: all authors. Drafting the article: Aldana, Youssef. Critically revising the article: Aldana, Youssef, Kraemer. Reviewed submitted version of manuscript: all authors. Approved the final version of the manuscript on behalf of all authors: Aldana. Statistical analysis: Smotherman, Kraemer. Administrative/technical/material support: Youssef, Smotherman, Kraemer. Study supervision: Aldana.

\section{Correspondence}

Philipp R. Aldana, Lucy Gooding Pediatric Neurosurgery Center, Wolfson Children's Hospital, 836 Prudential Dr., Ste. 1205, Pavilion Bldg., Jacksonville, FL 32207. email: philipp.aldana@ jax.ufl.edu. 